\title{
Erratum
}

\section{Postoperative Mortality After Esophagectomy for Cancer: Development of a Preoperative Risk Prediction Model}

\author{
Jin Ra, MD, ${ }^{1}$ E. Carter Paulson, MD, ${ }^{1}$ John Kucharczuk, MD, ${ }^{2}$ \\ Katrina Armstrong, MD, MSCE, ${ }^{3}$ Christopher Wirtalla, BA, ${ }^{1}$ \\ Rachel Rapaport-Kelz, MD, MSCE, ${ }^{4}$ Larry R. Kaiser, MD, ${ }^{2}$ and Francis R. Spitz, MD ${ }^{4,5,6}$ \\ ${ }^{1}$ Department of Surgery, Hospital of the University of Pennsylvania, Philadelphia, PA 19104, USA
${ }^{2}$ Division of Cardiothoracic Surgery, Department of Surgery, Hospital of the University of Pennsylvania, Philadelphia,
PA 19104, USA
${ }^{3}$ Department of General Internal Medicine, Hospital of the University of Pennsylvania, Philadelphia, PA 19104, USA \\ ${ }^{4}$ Department of Surgery, Division of Endocrine and Oncologic Surgery, Hospital of the University of Pennsylvania, Philadelphia, \\ PA 19104, USA \\ ${ }^{5}$ Department of Surgery, Philadelphia Veterans Administration Hospital, Philadelphia, PA, USA \\ ${ }^{6}$ Hospital of the University of Pennsylvania, 3400 Spruce Street, Philadelphia, PA 19104, USA
}

Erratum to: $10.1245 /$ s10434-008-9867-4

Annals of Surgical Oncology

The authors of the above mentioned article published online on April 1, 2008 wish to note that Table 3 was truncated and appeared incomplete in the article text. Table 3 is presented below in its entirety.
Published online November 13, 2008.

The online version of the original article can be found under doi: $10.1245 / \mathrm{s} 10434-008-9867-4$

Address correspondence and reprint requests to: Francis R. Spitz, MD; E-mail: fspitz@mail.med.upenn.edu

Published by Springer Science+Business Media, LLC @ 2008 The Society of Surgical Oncology, Inc.

TABLE 3. Multivariate analysis

\begin{tabular}{|c|c|c|c|c|}
\hline Variable & Beta coefficient & $P$ Value & Odds Ratio & 95\% C.I. \\
\hline \multicolumn{5}{|l|}{ Age } \\
\hline \multicolumn{5}{|l|}{ 65-69 } \\
\hline $70-79$ & 0.432 & .045 & 1.54 & $1.01-2.35$ \\
\hline $80+$ & 0.631 & .025 & 1.88 & $1.08-3.26$ \\
\hline \multicolumn{5}{|c|}{ Volume Center } \\
\hline \multicolumn{5}{|c|}{ High } \\
\hline Med & 0.521 & .026 & 1.68 & $1.07-2.66$ \\
\hline Low & 0.594 & .007 & 1.81 & $1.18-2.78$ \\
\hline \multicolumn{5}{|l|}{ Stage } \\
\hline \multicolumn{5}{|l|}{0} \\
\hline I & -0.535 & .189 & 0.58 & $0.26-1.30$ \\
\hline II & -0.288 & .399 & 0.74 & $0.38-1.46$ \\
\hline III & 0.014 & .966 & 1.01 & $0.51-2.00$ \\
\hline IV & 0.257 & .560 & 1.29 & $0.54-3.07$ \\
\hline N/A & -0.243 & .550 & 0.78 & $0.35-1.74$ \\
\hline \multicolumn{5}{|c|}{ Charlson Score } \\
\hline \multicolumn{5}{|c|}{0} \\
\hline 1 & -0.296 & .249 & 0.74 & $0.45-1.23$ \\
\hline $2+$ & 0.582 & .026 & 1.79 & $1.07-2.99$ \\
\hline \multicolumn{5}{|l|}{ Married } \\
\hline \multicolumn{5}{|l|}{ No } \\
\hline Yes & -0.251 & .185 & 0.77 & $0.54-1.13$ \\
\hline \multicolumn{5}{|l|}{ Sex } \\
\hline \multicolumn{5}{|l|}{$\mathrm{F}$} \\
\hline $\mathrm{M}$ & 0.031 & .883 & 1.03 & $0.68-1.57$ \\
\hline Race & & & & $0.46-2.12$ \\
\hline Other & & & & \\
\hline Black & -.011 & .978 & 0.99 & $0.46-2.12$ \\
\hline
\end{tabular}

